\title{
3-D hydrodynamic modelling of flood impacts on a building and indoor flooding processes
}

\author{
Bernhard Gems ${ }^{1}$, Bruno Mazzorana ${ }^{2}$, Thomas Hofer ${ }^{3}$, Michael Sturm ${ }^{1}$, Roman Gabl $^{1}$, and Markus Aufleger ${ }^{1}$ \\ ${ }^{1}$ Unit of Hydraulic Engineering, Institute for Infrastructure Engineering, University of Innsbruck, Innsbruck, 6020, Austria \\ ${ }^{2}$ Institute of Environmental and Evolutive Sciences, Faculty of Sciences, Universidad Austral de Chile, Valdivia, 14101, Chile \\ ${ }^{3}$ MWV Bauingenieure AG, Baden, 5400, Switzerland
}

Correspondence to: Bernhard Gems (bernhard.gems@uibk.ac.at)

Received: 26 November 2015 - Published in Nat. Hazards Earth Syst. Sci. Discuss.: 19 January 2016

Revised: 20 May 2016 - Accepted: 23 May 2016 - Published: 14 June 2016

\begin{abstract}
Given the current challenges in flood risk management and vulnerability assessment of buildings exposed to flood hazards, this study presents three-dimensional numerical modelling of torrential floods and its interaction with buildings. By means of a case study application, the FLOW3D software is applied to the lower reach of the Rio Vallarsa torrent in the village of Laives (Italy). A single-family house on the flood plain is therefore considered in detail. It is exposed to a 300-year flood hydrograph. Different building representation scenarios, including an entire impervious building envelope and the assumption of fully permeable doors, light shafts and windows, are analysed. The modelling results give insight into the flooding process of the building's interior, the impacting hydrodynamic forces on the exterior and interior walls, and further, they quantify the impact of the flooding of a building on the flow field on the surrounding flood plain. The presented study contributes to the development of a comprehensive physics-based vulnerability assessment framework. For pure water floods, this study presents the possibilities and limits of advanced numerical modelling techniques within flood risk management and, thereby, the planning of local structural protection measures.
\end{abstract}

\section{Introduction - vulnerability assessment within integral flood risk management}

Recently, researchers with different scientific backgrounds proposed major contributions to better understanding of the concept of vulnerability, each according to their specific disciplinary focus (Hufschmidt, 2011; Fuchs, 2009). When ad- dressing vulnerability, social scientists traditionally tend to emphasise the characteristics of people or communities in terms of their capacity to anticipate, cope with, resist, and recover from the impact of a hazard (e.g. Wisner, 2004). In contrast, from a purely engineering perspective, vulnerability is defined as the degree of loss incurred by an element at risk as a result of a hazard impact with a given intensity and frequency (Fell et al., 2008). Vulnerability is thereby assessed on the basis of empirical data and/or scenario modelling.

The efforts to increase the resilience of communities towards natural hazards have to be devoted (i) to a substantial reduction of the vulnerability of the built environment (e.g. critical infrastructure, residential buildings) and (ii) to the promotion of management actions with respect to the different possibilities given by the risk management cycle in Fig. 1.

Regarding the respective societal framework, risk assessment is targeted at the evaluation of risk, which includes (i) a social assessment of the level of risk to be accepted, (ii) an economic valuation of possible mitigation activities vs. the level of risk reduction achieved by these measures, (iii) a general assessment of individual and societal risk awareness and acceptance as well as (iv) possibilities of risk mitigation. Optimal mitigation strategies seek to address the different and interrelated dimensions of vulnerability such as economic, institutional, physical (structural) and social vulnerability. Hereby, the reduction of physical vulnerability is seen as a starting point, resulting directly in a reduction of physical losses and indirectly in a mitigation of possible consequences with respect to the other dimensions of vulnerability (Kappes et al., 2012a, b; Papathoma-Köhle et al., 2011; Fuchs, 2009). This implies that vulnerability assessment should meet high- 


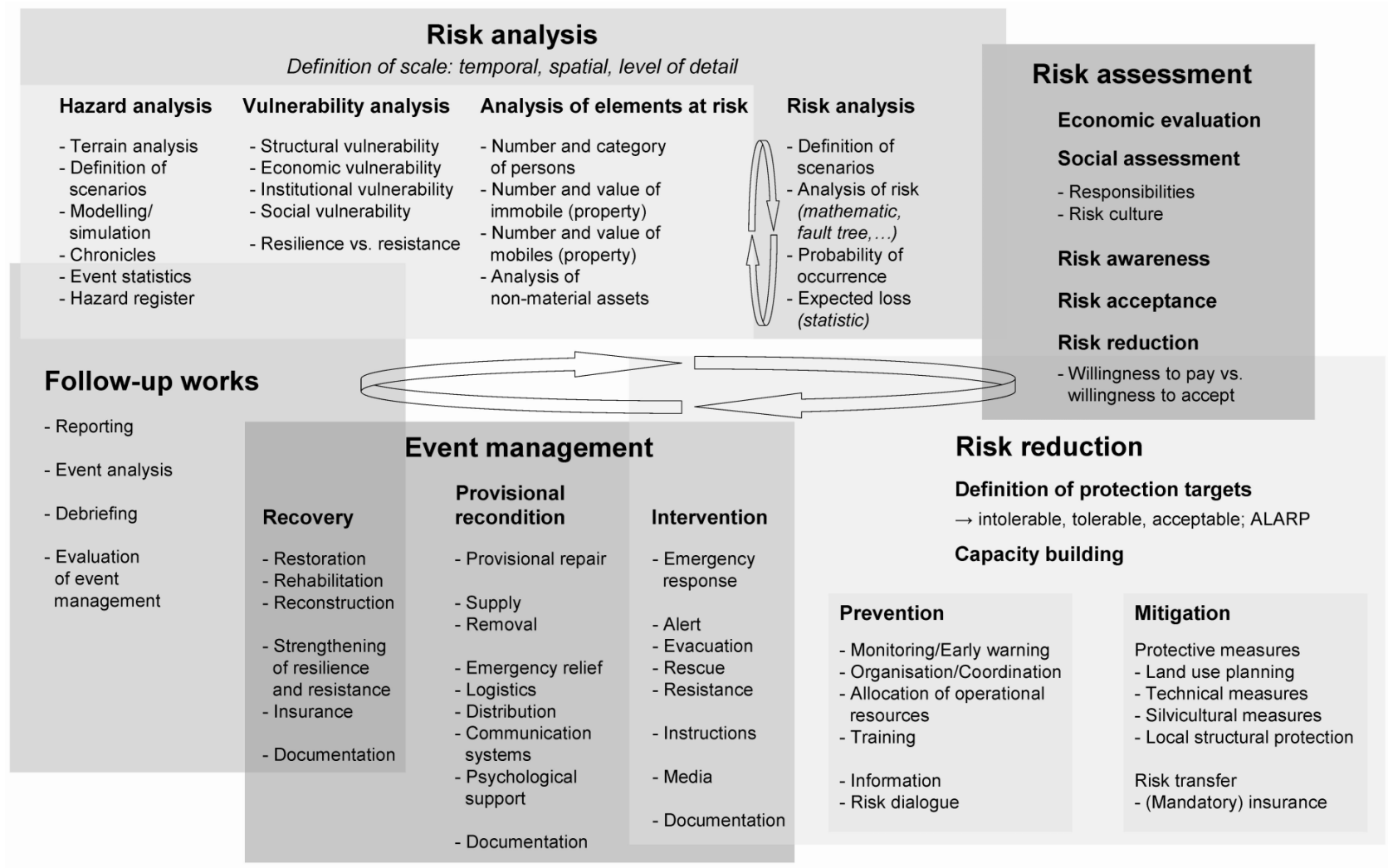

Figure 1. The model of integral risk management conceptualised as "risk cycle" (adapted from Carter, 1991; Alexander, 2000; Kienholz et al., 2004), based on an earlier version in www.nahris.ch and adapted from Fuchs (2009).

quality standards to provide for an integrated knowledge basis for all relevant management options, including the design of appropriate mitigation measures and the policy implementation during necessary decision-making actions.

Amongst others, integral risk management covers structural (technical) measures for protection against natural hazards. Aiming for the reduction of risk, they actively decrease hazard potential. For the case of torrential hazards, afforestation measures, erosion control, check dams and levees are typically applied. If the damage potential is decreased, e.g. in terms of object protection, technical measures have a passive effect. Basically, hazard analysis by means of experimental and numerical modelling of relevant scenarios became increasingly important in the recent past. In the case of numerical modelling, significant advances in modelling techniques and the augmented computational power presently allow for analyses of complex issues and scenarios (e.g. Gems et al., 2014a, b; Mazzorana et al., 2014; Chiari, 2008). They enable the simulation of hazard processes on a large spatial scale (e.g. Gems, 2014c; Gems et al., 2012). Hydraulic scale models are created mostly to address and model complex problem settings, geometrical configurations and compound scenarios, e.g. morphodynamics (sediment transport) in a complex three-dimensional flow field, flow-structure interaction and the bed load transport involved, and the impacts of hazard processes on structures (e.g. Scheidl et al., 2013; Armanini and Scotton, 1992). Experimental modelling is restricted to a rather limited spatial scale.

Research efforts in the field of integral flood risk management and, thereby, hazard analysis and modelling (Fig. 1) have been devoted to study the physical vulnerability of buildings exposed to fluvial hazard processes facing (i) the aim to compute vulnerability functions for use in risk assessment (Totschnig and Fuchs, 2013; Papathoma-Köhle et al., 2012; Fuchs et al., 2007) and (ii) the design of local structural protection measures (Holub et al., 2012). Despite these efforts, considerable research questions still remained unanswered: while studies firstly combined empirical loss data with information on process intensities and resulted in damage-loss or vulnerability functions, the latter studies were mainly from a practical perspective on the reduction of structural vulnerability of individual buildings. Due to the underlying empiricism of such vulnerability functions, the physics of the damage-generating mechanisms remains unveiled, and, as such, the applicability of the empirical approach for planning hazard-proof buildings is rather limited. Mazzorana et al. (2014) identified the following essential requirements for vulnerability assessment of buildings exposed to fluvial hazard processes. 
a. A comprehensive methodology of vulnerability assessment requires a physics-based approach with a detailed representation of the impacting hazard process, both with respect to space and time.

b. Quantification of the resulting impacts on a building envelope and detection of possible material intrusion processes require an analysis of the geometrical structure of the building with respect to the time-varying flow field of the impacting process and, if geo-mechanical actions may interfere, with respect to the residual bearing capacity of the soil layers in which the object is situated.

c. A physical response (resistance) analysis of the building structure considering the time-varying impacts is required, both, from a structural analysis perspective (statics, elastostatics and dynamics) and a building physics viewpoint. Stresses and strains on the building have to be compared with maximum admissible values (according to the set of norms EN 1990 (Eurocode 0: Basis of Structural Design), EN 1991 (Eurocode 1: Actions on Structures) and the specific design codes EN 1992 to EN 1999).

Referring to these basic requirements, Mazzorana et al. (2014) defined a five-step procedure according to Fig. 2 in order to reliably assess the physical vulnerability of elements at risk. The proposed concept is directed at unveiling the sequences of significant loss generation mechanisms, both methodologically and computationally. By evaluating potential damages, the scope of vulnerability assessment is expanded beyond its classical role as a decision-support tool and is closely linked to the planning process of torrent control measures. The workflow requires the definition of a suitable control volume and convenient control sections for every considered element at risk. Process and impact modelling (steps A and B according to Fig. 2) lead to a spatially explicit and time-varying quantification of actions and effects on the building structure. The response model (step $\mathrm{C}$ according to Fig. 2) consists of the verification of (i) a set of limit states according EN 1990 (ultimate limit states ULS and serviceability limit states SLS) and of (ii) the non-intrusion condition for the liquid and solid material. Details on the steps of damage accounting and economic loss valuation are also covered in Mazzorana et al. (2012a, b, 2013).

Within the context of an analysis of a torrential hazard event, thereby explicitly focusing on the morphodynamic processes and not taking into account any geo-mechanical processes or the building's physics, Mazzorana et al. (2014) applied the proposed concept for a residential building located at the alluvial cone of the Grossberg torrent in the Italian Alps. The study highlighted the circumstance that for medium hazard intensities, vulnerability of buildings critically depends on the patterns of water and material intrusion through openings such as doors, light shafts and windows. In addition to the proper consideration of the resistance of the considered building in terms of the physical impact and the structural response, also the physical processes taking place on and throughout the building envelope (e.g. material intrusion and moisture transfer and accumulation, wetting and drying of the outer and inner layers of the building) are found to be relevant within vulnerability assessment.

Due to a lack of data from fundamental research and software limitations, Mazzorana et al. (2014) neither considered specific processes and analytical steps of the assessment scheme (Fig. 2) nor did they analyse them by using empirical data and models, mainly the following.

a. The transformation of process parameters (flow depths and velocities, bed level changes) to impact parameters (static and dynamic loadings) is based on straightforward empirical approaches, estimating the impact of torrent hazards on idealised surfaces.

b. The processes of water and material intrusion and consequential impacts on the building envelope and on the damage pattern are not considered.

c. The economic valuation (damage estimation) is based on the application of empirical damage functions connecting the loss to the maximum impacting flow depths. However, any dynamics and time-varying process patterns (wetting areas and durations, fluid forces, etc.) have some influence on the impact and response models and thus on the profiles of damage consequences.

d. The applied case study explicitly considers one specific element at risk. Thus, and also due to the nonconsideration of material intrusion processes, any interaction of the relevant elements at risk situated on the Grossberg alluvial cone has not been analysed. Accordingly, also a geostatistical analysis focusing on the damage patterns and interaction of specific elements at risk situated at different spots on the alluvial cone has not been carried out.

In the context of the proposed procedure (based on Mazzorana et al., 2014), the present paper focuses on the hydrodynamic simulation of indoor flooding processes. A case study analysis is completed for a specific element at risk, situated close to a torrential stream in the Italian Alps. The flow field in the lower reach of the torrent channel, the flood plain in the near surroundings of the considered building and the building's flooding processes are modelled with the FLOW-3D software (Flow Science Inc., 2012), both for a set of steady and unsteady flow conditions. Regarding the aforementioned issues (a) to (c), mutual influences of the flow fields inside and outside of the building are analysed. Further, impacts on load-bearing walls of the building are evaluated discretely in space and time.

Flood hazard processes that impact, enter and flood a building envelope have not yet been sufficiently examined with experiments or a numerical model. Therefore the 


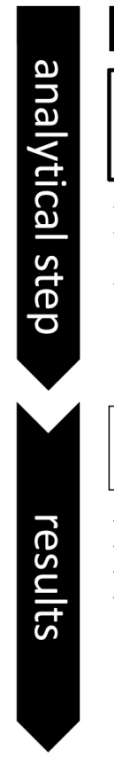

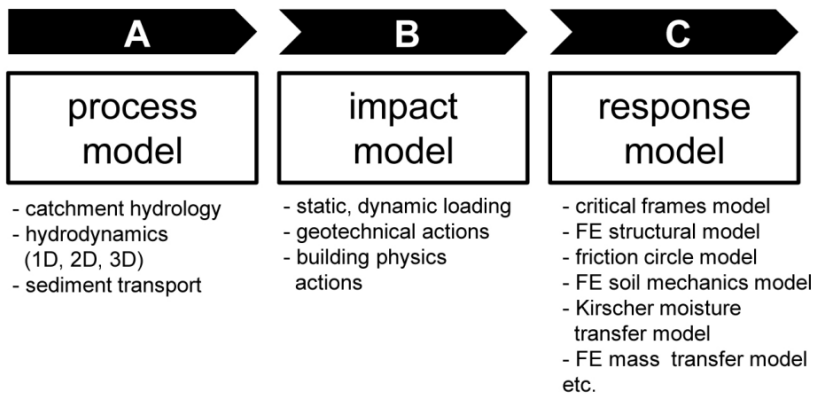

spatially explicit and time-varying representation of hazard processes parameters, impacts and system response

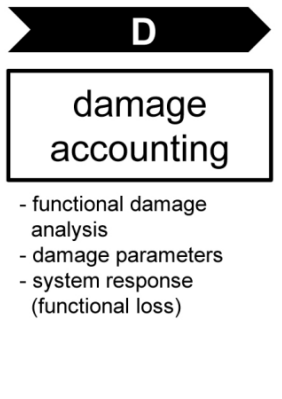

profiles of damage consequences

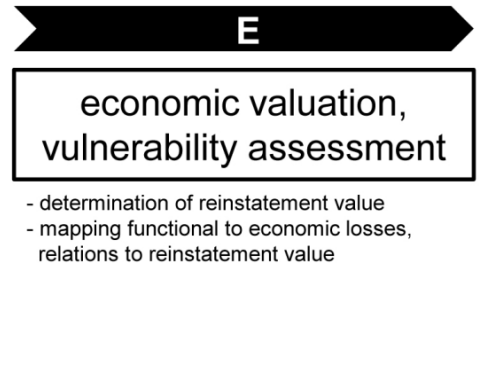

economic loss in absolute terms, building specific vulnerability

$\begin{array}{lcc}\text { - flow velocities } & \text { - forces / pressure on } & \text { - stresses, strains in structure } \\ \text { - fow depths } & \text { the building envelope } & \text { - maximum permissible } \\ \text { - pressure } & \text { - construction - slope } & \text { impacts } \\ \text { - erosion / aggradation } & \text { system representation } & \text { - safety factors for slope } \\ \text { processes } & \text { - wetted surfaces } & \text { stability } \\ & \text { - intrusion pathways } & \text { - modified bearing capacities } \\ & \text { - response to wetting } \\ & \text { - intruded solid material volume } \\ & \text { - damage suceptebility profiles } \\ & \text { etc. }\end{array}$

Figure 2. Proposed physics-based vulnerability assessment scheme according Mazzorana et al. (2014) (modified).

present case study analysis is a priori-constrained to pure water floods (WFL according to Heiser et al., 2015) and aimed mainly at the following research questions.

- If constraining to pure water floods (WFL) with no involvement of bed load (Heiser et al., 2015), is there a relevant dynamic impact of the entraining water on the building structure and a noticeable influence on the flow field on the surrounding flood plain?

- With regard to the planning process of local structural protection measures, does the simulation of building flooding processes provide any beneficial information?

- From the perspective of computational capacity and practical application, e.g. for flood plain mapping and hazard zone planning respectively, is it feasible to enlarge the simulation area to a larger extent in order to cover a couple of buildings and objects?

\section{Case study analysis}

\subsection{Introduction and modelling assumptions}

Referring to the aforementioned introduction in vulnerability assessment and the consideration of mutual influences of flood hazard processes and buildings, the work presented within this paper deals with the simulation of building flooding processes, their influences on the adjacent flow field and the determination of impacting forces on a building structure. In the sense of a case study analysis, focus is put on the flood plain at the Rio Vallarsa in the village of Laives (Autonomous Region of Trentino-Alto Adige, Italy, Fig. 3). One specific element at risk, which is distinctly prone to flooding in the case of a torrential hazard event, is considered to be a permeable structure within hydrodynamic 3-D numerical modelling (Fig. 5). Therein, solely impacts of pure water floods (WFL according Heiser et al., 2015) are analysed. Any expected influence of sediments, substantially (i) loss of flow capacity in the torrent channel due to the transport of bed load (Gems et al., 2014a, b; Hübl et al., 2002; Hunzinger and Zarn, 1996), (ii) intrusion of sediments into the element at risk and (iii) a significant increase of impacting forces compared to clear water conditions (Mazzorana et al., 2014), are not considered.

The following two basic aspects support the disregard of bed load transport processes in this specific case.

a. Referring to the characteristics of the Rio Vallarsa catchment and the damage causing torrential hazard processes (Sect. 2.2), a deposition basin including a debris retention dam is located at the alluvial cone closely upstream the case study area (Fig. 3). The basin volume corresponds to the expected amount of sediment during a 150 -year design event in the catchment. Bed load is not expected to pass the concrete dam; thus, the downstream channel is loaded with pure water hydrographs only.

b. Modelling of building flooding (discharge) and intrusion (sediment) processes is a topic of current basic research and not yet explicitly considered within flood risk management, at least in the Alpine space. Reflecting capabilities and limits of numerical models, the simulation of torrential floods with intense sediment loads (WST and DBF according Heiser et al., 2015) is cur- 

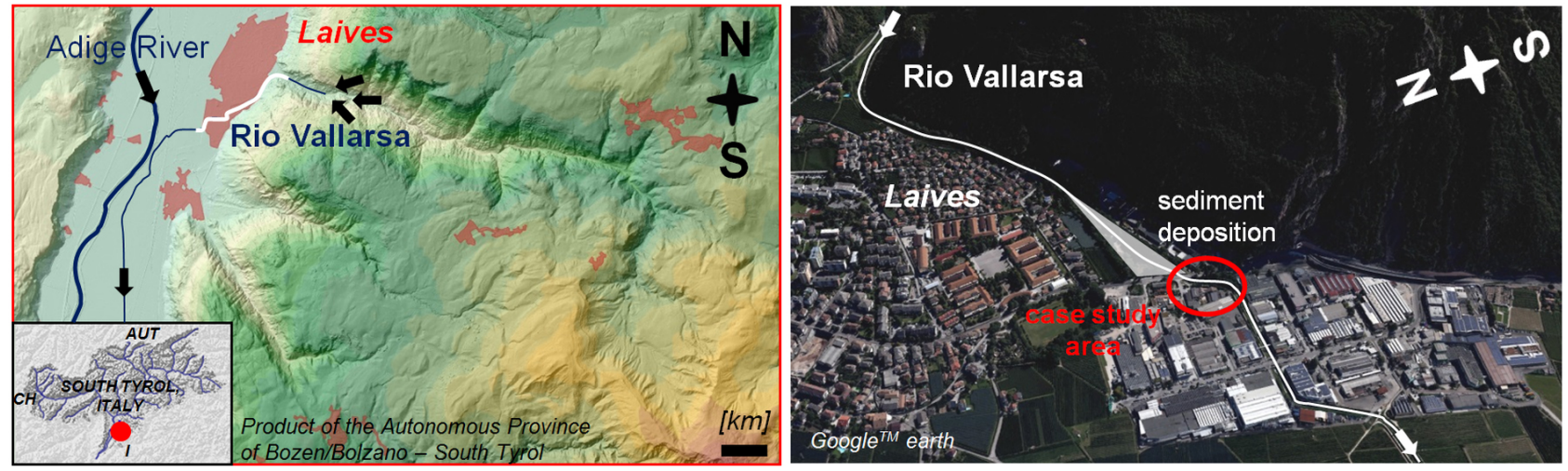

Figure 3. (Left) overview of the Rio Vallarsa catchment and the Adige valley at the village of Laives (Italy); the colour scheme characterises an elevation model with a $2.5 \mathrm{~m}$ interval. (Right) track of the Rio Vallarsa torrent channel through settlement and commercial area in the south-western part of Laives; location of the case study area on the alluvial cone.

rently restricted to 2-D numerical codes (e.g. Vetsch et al., 2014; Rosatti and Begnudelli, 2013). This contrasts with the requirement of a three-dimensional approach, which is performed when the flow field is intended to be numerically modelled in- and outside of a complex building structure (featuring several floors and openings as doors, light shafts, windows, etc.). Further, from the perspective of computational demand, applications of 3-D numerical codes are basically limited to rather small river sections and small-scaled areas respectively (Gabl et al., 2014; Gems et al., 2014a; Habersack et al., 2007). Against this background, the presented case study analysis is intended to focus on a specific building and its immediate sphere of influence. The simulations are aimed for use in the context of physics-based vulnerability analysis (Mazzorana et al., 2014) and the planning of local structural protection measures rather than large-scale inundation mapping. Thereby, subjects of investigation are also computational effort and limits of numerically modelling the building-fluid interaction, each from a practical perspective.

\subsection{Catchment and building characteristics - hazard and damage potential}

The Rio Vallarsa catchment is situated to the south of Bolzano (Italy). Covering $29.4 \mathrm{~km}^{2}$ and ranging from $230 \mathrm{~m}$ at Laives to $1550 \mathrm{~m}$ above sea level, it represents a tributary catchment to the Adige River. The catchment extends mainly in an east-west direction. From a geological perspective, the catchment is shaped by the Bozen quartz porphyry (in.ge.na engineering office, unpublished). In the upper catchment part, marginal incisions in glacial deposits and gully erosion characterise the trunk torrent. A straight-line channel with moderate gradients and a few small tributaries can be observed in the middle part of the catchment. Further downstream, the Rio Vallarsa passes a rather narrow and deeply incised canyon before entering the spacious Adige valley at the village of Laives. The torrent passes the settlement area of Laives on the south-west periphery along the border of the valley floor. After leading along the agricultural area, the channel enters the Adige River in the village of Ora.

Both, fluviatile and debris flow regimes characterise observed torrential hazard events in the middle and upper catchment and as well the upper section on the alluvial cone (in.ge.na engineering office, unpublished; Fig. 3). Due to a sufficiently dimensioned sediment deposition basin at Laives (Fig. 3), flood discharges without significant fractions of sediment threaten the settlement and commercial areas further down the deposition basin (in.ge.na engineering office, unpublished).

With regard to the hydrogeological hazard analysis done by in.ge.na engineering office (unpublished), the 100-year flood peak (HQ100) of the Rio Vallarsa at the village of Laives amounts to $35 \mathrm{~m}^{3} \mathrm{~s}^{-1}$. The 300 -year flood peak (HQ300) is estimated to $55 \mathrm{~m}^{3} \mathrm{~s}^{-1}$. The study is based on the common assumption of equal return periods of impacting design precipitation and discharge. The statistical rainfall analysis is thereby based on observed data from the monitoring station at Bronzolo, which is situated $3 \mathrm{~km}$ south of Laives at an altitude of $250 \mathrm{~m}$ a.s.l. However, a reconstruction analysis of the flood event in November 2012, which basically featured a peak discharge of $55 \mathrm{~m}^{3} \mathrm{~s}^{-1}$ and bankfull flow conditions in the channel at Laives, indicates higher peaks for the 100- and 300-year event. It was analysed that the observed rainfall intensities and durations in November 2012 featured clearly lower return periods. Consequently, the design flood hydrographs were modified accordingly (Department of Hydraulic Engineering, Autonomous Province of Bolzano, unpublished), amongst leading to a decrease of the $55 \mathrm{~m}^{3} \mathrm{~s}^{-1}$-return period to about 5 years. Based on these latest data and analyses, sufficient protection against torrential hazards from the Rio Vallarsa catchment is not fulfilled at Laives, since flooding of the rigid torrent channel is al- 
ready expected for discharges around HQ10 (Department of Hydraulic Engineering, Autonomous Province of Bolzano, unpublished). Buildings and infrastructure in close proximity to the torrent channel are threatened of being flooded in the case of a torrential hazard event.

Figure 3 illustrates the situation at the southern part of the alluvial cone at Laives and the track of the Rio Vallarsa torrent. Therein, the case study area is situated straight down the deposition basin. It covers roughly $170 \mathrm{~m}$ of the trapezoidal rigid torrent channel, which features a gradient of $1.1 \%$ and a cross section area of $19.5 \mathrm{~m}^{2}$. It is a brick work channel lined with cement mortar, whereby the channel side walls are partially covered with vegetation. The surrounding flood plain is further considered along this channel section. The main focus within numerical modelling is put on one specific building, situated orographically right in a distance of approximately $17 \mathrm{~m}$ to the channel.

Figure 4 presents a perspective view of the considered building and shows top views of both, the building's basement level and the first floor. With a floor area spanning approximately $130 \mathrm{~m}^{2}$, the building features a rather complex structure, including a couple of potential openings for flooding, such as doors, light shafts and windows. With regard to the numerical model (Sect. 2.4) and the analysis of the simulation results (Sect. 2.5), the structural elements of the building are labelled accordingly. Further information on the structural elements of the building and the potential openings for indoor flooding processes is given in Sect. 2.3 (Table 1).

\subsection{Hazard and building scenarios}

A 300-year flood event is considered within hydrodynamic numerical modelling. In accordance with the reconstruction analysis of the flood event in November 2012 and further hydrological catchment analyses (Department of Hydraulic Engineering, Autonomous Province of Bolzano, unpublished), the corresponding peak discharge amounts to $120 \mathrm{~m}^{3} \mathrm{~s}^{-1}$. The simulations are carried out in an unsteady mode, approaching the expected 300-year flood hydrograph. Due to the computational effort, the simulations do not cover the entire design hydrograph. The investigation focuses on the rising limb of the design hydrograph, when the discharge exceeds $30 \mathrm{~m}^{3} \mathrm{~s}^{-1}$, and continue until the discharge falls below $30 \mathrm{~m}^{3} \mathrm{~s}^{-1}$ again in the falling limb. A discharge of $30 \mathrm{~m}^{3} \mathrm{~s}^{-1}$ amounts to roughly $60 \%$ of the HQ5 discharge and already leads to initial flooding of the cycle track at the bridge (Hofer, 2014). In order to keep the computational effort for the unsteady model simulations manageable, the simulation hydrograph is chronologically scaled by a factor of 0.1 compared to the expected flood hydrograph under prototype conditions. With it, the computation time for the unsteady hazard scenario is $1020 \mathrm{~s}$, and the total discharge volume entering the computational domain amounts to $720270 \mathrm{~m}^{3}$.

Representing a preliminary study to this unsteady hazard scenario, steady-state simulations with the discharges 87 and
$104 \mathrm{~m}^{3} \mathrm{~s}^{-1}$ and the 300 -year peak discharge $120 \mathrm{~m}^{3} \mathrm{~s}^{-1}$ were also carried out. For this study, simulation results and any further details are presented by Hofer (2014). The discussion of the simulation results (Sect. 3.2) merely gives a very brief summary of it. Further, the influence of the simulation mode or rather the considered hazard scenario on the fluidbuilding interaction is analysed by qualitatively and quantitatively comparing the results of the unsteady and steady-state simulations.

Concerning the implementation of the considered element at risk in the numerical model, three scenarios are analysed. Each is characterised by a certain degree of mutual influence between the building and the flow field on the surrounding flood plain. Scenario (a) treats the building as a fully blocked structure, not enabling any indoor flooding processes. The building envelope is thereby in accordance with the perspective view in Fig. 4. All doors, light shafts and windows are permanently blocked. Table 1 illustrates the features of the wall elements e1-e7 on the first floor of the building envelope (Fig. 4). Concerning the listed wall areas, the dimensions of windows and doors are not included therein, although assumed to be closed for this scenario. Reflecting current standard practice and methods in flood risk management and, more specifically, the consideration of buildings within inundation mapping (e.g. Tsakiris, 2014; Habersack et al., 2007), scenario (a) with a fully blocked building represents the reference case for further scenarios.

With scenario (b), the building is treated as a permeable structure. All openings are set permanently and entirely open. This assumption runs contrary to scenario (a); however, it does also not fully conform to typical natural conditions. Also for scenario (b), the features of the wall elements (first floor) are listed in Table 1. In this case, wall surfaces inside the building and on the outside are separately considered with components each in the numerical model in order to allow for an individual analysis of wetted areas and fluid forces acting on the walls.

As shown in the perspective view in Fig. 4, the building features a couple of openings on its south-west and west sides, both directly facing to the Rio Vallarsa channel. Dealing with the efficacy of local structural protection measures, scenario (c) further considers specific permanent modifications at the building, which are intended to reduce or best possibly prevent the fluid from flooding critical spots within the building. There, the light shafts s1, s4 and s5 (Fig. 4) are closed with a cover and the top levels of the light shafts s2 and $\mathrm{s} 3$ are raised by $0.8 \mathrm{~m}$ to a level which is expected to overtower the critical flow depth on the surrounding flood plain. Remaining openings of the building envelope are considered to be open, which is in accordance with the setting of scenario (b).

Concerning the results of scenario simulation, the study is intended to point out the influence of local structural protection measures on the spatial and temporal progression of fluid influx. Basically, a full prevention of fluid influx into 
Table 1. Building representation for the considered scenarios (a), with a fully blocked structure, and (b), assuming all doors, light shafts and windows to be entirely open; wall element notations refer to Fig. 4; for scenario (b), index "o" means the outside of the wall element, and "i" refers to the inside.

\begin{tabular}{|c|c|c|c|c|c|c|c|c|}
\hline & \multicolumn{8}{|c|}{ Building representation - first floor } \\
\hline & \multirow{2}{*}{$\begin{array}{l}\text { Wall } \\
\text { element }\end{array}$} & \multirow{2}{*}{$\begin{array}{l}\text { Total area } \\
\left(\mathrm{m}^{2}\right)\end{array}$} & \multicolumn{2}{|c|}{ Doors } & \multicolumn{2}{|c|}{ Windows } & \multirow{2}{*}{$\begin{array}{l}\text { Wall area } \\
\left(\mathrm{m}^{2}\right)\end{array}$} & \multirow{2}{*}{$\begin{array}{l}\text { Wall length } \\
\text { (m) }\end{array}$} \\
\hline & & & Number & $\left(\mathrm{m}^{2}\right)$ & Number & $\left(\mathrm{m}^{2}\right)$ & & \\
\hline \multirow{7}{*}{ Scenario (a) - blocked structure } & e1 & 13.44 & 2 & 3.84 & 1 & 1.09 & 8.51 & 2.20 \\
\hline & e2 & 7.46 & 1 & 2.02 & - & - & 5.44 & 1.33 \\
\hline & e3 & 19.05 & - & - & 2 & 2.34 & 16.71 & 5.95 \\
\hline & e4 & 1.91 & - & - & - & - & 1.91 & 0.59 \\
\hline & e5 & 13.44 & - & - & 1 & 1.19 & 12.25 & 4.20 \\
\hline & e6 & 33.28 & - & - & 2 & 3.98 & 29.30 & 10.4 \\
\hline & $\mathrm{e} 7$ & 46.03 & 4 & 13.30 & - & - & 32.73 & 7.73 \\
\hline \multirow{14}{*}{ Scenario (b) - permeable structure } & e1-o & 13.44 & 2 & 3.84 & 1 & 1.09 & 8.51 & 2.2 \\
\hline & e1-i & 13.73 & 2 & 3.84 & 1 & 1.09 & 8.80 & 2.36 \\
\hline & e2-o & 7.46 & 1 & 2.02 & - & - & 5.44 & 1.33 \\
\hline & e2-i & 6.02 & 1 & 2.02 & - & - & 4.00 & 0.88 \\
\hline & e3-o & 19.05 & - & - & 2 & 2.34 & 16.71 & 5.95 \\
\hline & e3-i & 16.48 & - & - & 2 & 2.34 & 14.14 & 5.15 \\
\hline & e4-o & 1.91 & - & - & - & - & 1.91 & 0.59 \\
\hline & e4-i & 2.05 & - & - & - & - & 2.05 & 0.64 \\
\hline & e5-o & 13.44 & 1 & - & 1 & 1.19 & 12.25 & 4.20 \\
\hline & e5-i & 12.80 & 1 & - & 1 & 1.19 & 11.61 & 4.00 \\
\hline & e6-o & 33.28 & - & - & 2 & 3.98 & 29.30 & 10.40 \\
\hline & e6-i & 30.72 & - & - & 2 & 3.98 & 26.74 & 9.60 \\
\hline & e7-o & 46.03 & 4 & 13.30 & - & - & 32.73 & 7.73 \\
\hline & e7-i & 42.50 & 4 & 13.30 & - & - & 29.20 & 6.63 \\
\hline
\end{tabular}
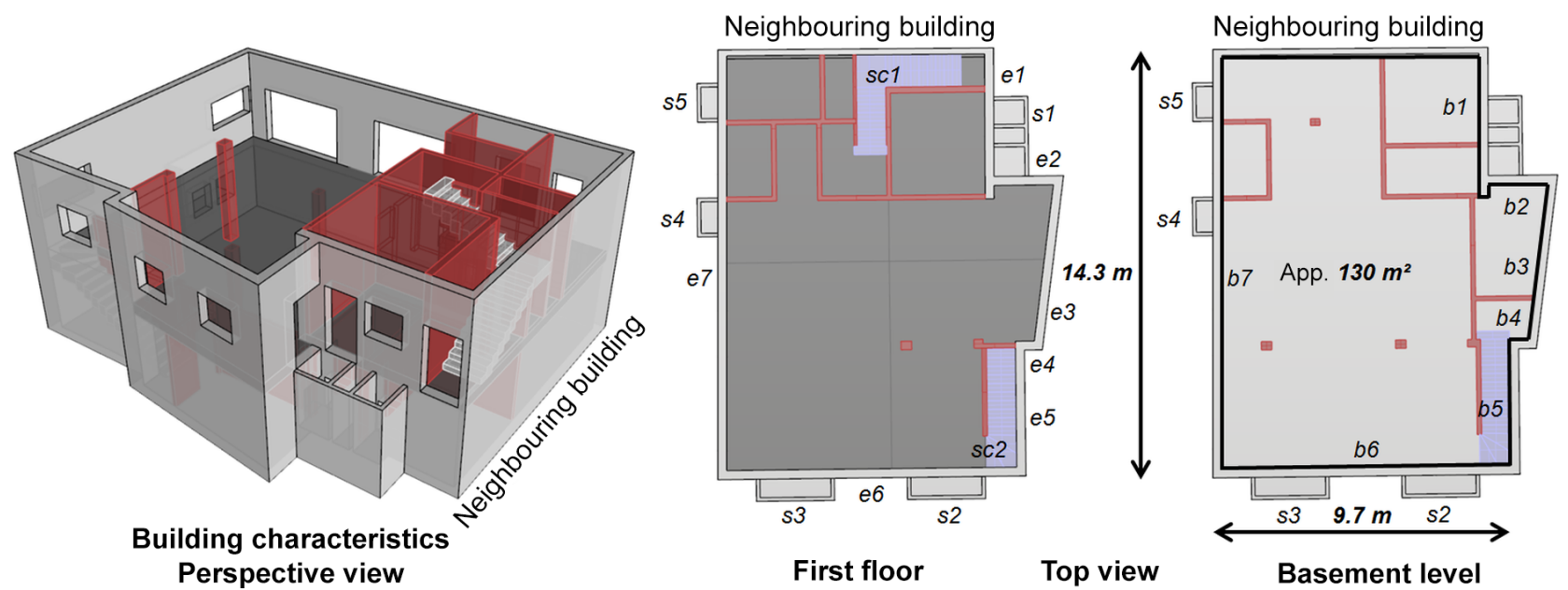

Figure 4. Object of investigation within 3-D hydrodynamic modelling - (left) perspective view and (middle, right) top views of first floor and basement level; notations e1-e7 identify exterior walls on the first floor, b1-b7 denote to corresponding wall elements on the basement level; inner walls are coloured red, s1-s5 characterise light shafts and sc1-sc2 identify stair cases (coloured blue).

the building with the measures tested in scenario (c) is not expected.

For all building scenarios (a), (b) and (c), both the steadystate events and as well the unsteady torrential hazard scenario are computed.

\subsection{Numerical model}

Hydrodynamic numerical modelling is carried out with the FLOW-3D software (Flow Science Inc., 2012). The model 
scheme and a perspective view of the FAVOR-model (Flow Science Inc., 2012) are illustrated in Fig. 5.

The computational domain, basically covering the section of the brick work channel of the Rio Vallarsa (Sect. 2.2) and the surrounding flood plain orographically right to the channel, is meshed with six structured, orthogonal mesh blocks $(\mathrm{mb})$. The grid resolution is equally set to $0.167 \mathrm{~m} \times 0.167 \mathrm{~m} \times 0.167 \mathrm{~m}$ for every mesh block. The input boundary is defined as a bottom inlet, represented by two small and accurately defined areas at the upstream model boundary and inflow velocities in a positive vertical direction. At the model outlets on the flood plain, pressure boundary conditions are set, each with the assumption that unrealistic backwater effects can be excluded. As illustrated in the model scheme in Fig. 5, pressure boundary conditions are set at the Xmin, Ymin and Ymax boundary of mesh block $\mathrm{mb} 2$. At the downstream edge of the channel, the boundary condition "outflow", coping best with a varying discharge at the un-gaged model boundary (Hofer, 2014), is applied. Concerning both, the grid resolution and the boundaries, comprehensive tests on their influence on the flow field within the computational domain have been carried out by Hofer (2014), amongst simulations with uniform grid resolutions of $0.33,0.167$ and $0.25 \mathrm{~m}$. Related to the modelling results with the grid size of $0.167 \mathrm{~m}$, relative differences in flow depths and velocities of $1.75 \%$ and $10 \%$ at maximum in the channel were analysed. Mesh refining from a grid size of 0.167 to $0.125 \mathrm{~m}$ increased the computation times by a factor of 5 . An influence of the grid resolution on the model stability was not observed thereby and the adaptive (and in FLOW-3D internally controlled) computational time step decreased with increasing grid resolution. Therefore, with regard to accuracy and computational effort, the mentioned grid resolution offers an optimal compromise (Hofer, 2014). Mesh block mb6 is set due to the fact that in the case of higher discharges, the flow enters also the cycle path in the near range of the bridge. Mesh block mb6 allows for a spreading along the cycle path towards upstream without reaching the Ymax boundary of the mesh block.

The considered building is situated within mesh block mb2. Depending on the considered building scenario (Sect. 2.3), it is modelled as blocked or permeable structure or rather a structure with local structural protection measures. In order to individually analyse wetted areas and force magnitudes on the wall elements, every element is implemented as an individual component in the model. Further, to distinguish between impacts inside the building and on the outside, the wall elements of the first floor are modelled with two components each, partially overlapping each other and shaping the wall structure together (Hofer, 2014). The remaining buildings and objects are modelled as blocked objects. The 3D numerical model contains 7.05 million cells. Thereof, 2.65 million cells represent active cells for the simulation (for scenario b).
With regard to a plausibility check of the numerical modelling results and, thereby, an appropriate definition of additional roughness parameters for the channel section and the flood plain, no flood events have been observed in the recent past that caused relevant flooding or damages in the case study area. As already stated in Sect. 2.3, the peak discharge $55 \mathrm{~m}^{3} \mathrm{~s}^{-1}$, observed in November 2012, caused bankfull flow conditions in the channel. This information was used for the calibration of the numerical model of the channel geometry by adjusting the corresponding roughness parameters. The model thus leads to overbank flooding at discharges of about $60 \mathrm{~m}^{3} \mathrm{~s}^{-1}$ (Hofer, 2014), and this adequately fits with available information and expert assessment (Department of Hydraulic Engineering, Autonomous Province of Bolzano, unpublished). Since any observation data is not available on the flood plain and for the building structure, roughness parameters are set to characteristic values commonly cited in the literature (e.g. Giesecke et al., 2014; Landesanstalt für Umweltschutz Baden-Württemberg, 2002). The spatial extent of specific surface structures and vegetation is adequately considered thereby. The chosen additional roughness coefficients are mentioned in Fig. 5.

Concerning the turbulence options in the numerical simulations, the standard two-equation $\mathrm{k}-\epsilon$-turbulence model is set.

\subsection{Results of unsteady hydrodynamic modelling}

Figure 6 illustrates snap shots of the simulation for scenario (b) with the assumption of a permeable building envelope. Perspective views of the computational domain at four different time frames are pictured. The colouring of the fluid isosurface denotes to the total hydraulic head, which includes water depth and velocity head. The isosurface value is thereby set to 0.25 in order to illustrate very low water depths on the outer channel embankment. Further, the flow rates at the channel in- and outflow of mesh block mb1 (Fig. 5) point out the maximum discharge capacity in the channel and the fluid volume impacting the adjacent flood plain. Negative flow rates at the mesh block boundaries are due to the orientation of the coordinate system set for the computations.

Generally, flooding at discharges exceeding $60 \mathrm{~m}^{3} \mathrm{~s}^{-1} \mathrm{oc}-$ curs mainly at the outside of the channel bend immediately after the bridge crossing. This basically confirms the observations during the flood event in November 2012 (Sect. 2.2). After roughly $285 \mathrm{~s}$ of simulation, flooding initially reaches the building envelope and starts wetting. Due to the enclosing wall of the neighbouring building, flooding is to some extent deflected to the south- and south-west faces of the building, at least when the flooding process has not made much progress yet. With it, indoor flooding is initially observed at the light shafts $\mathrm{s} 2$ and $\mathrm{s} 3$ on the short side of the building. The basement level is filled and after around $450 \mathrm{~s}$ of simulation, flow depths significantly increase also in the first floor of the building. The flow exits the building mainly on the building 

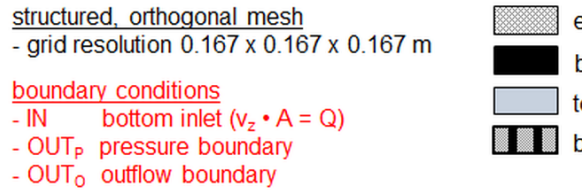
element at risk blocked objects torrent channel bridge structure (with piers)
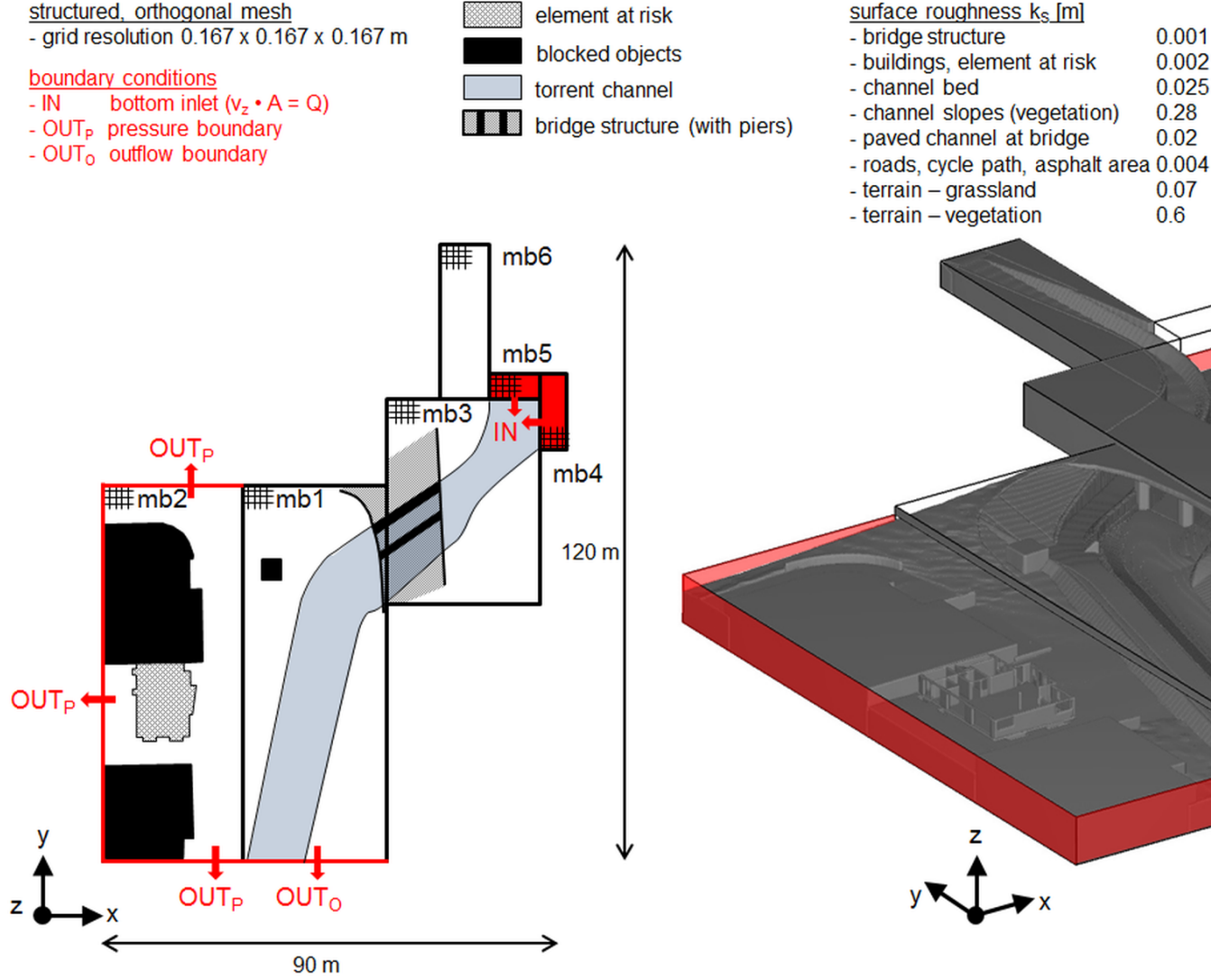

model scheme

FAVOR-model

Figure 5. (Left) scheme of the hydrodynamic numerical model; (right) computational model representation with the FAVOR-method (Flow Science Inc., 2012).

side opposite to the channel via the light shafts s4 and s5 from the basement level and the openings of wall element e7 on the first floor. Within the falling limb of the hydrograph, the flow depths in the building and on the surrounding flood plain decrease again. However, the basement level of the building remains fully filled up to the level of the ceiling of the storey in question. It should be noted that the storey ceiling is not figured out in Fig. 6, it is of course considered within numerical modelling. Wall elements of the basement level are coloured red in Fig. 6. Those of the first floor have a white colour.

To give a further impression on the characteristics of influx into in the building structure and flow conditions inside, Fig. 7 illustrates depth averaged velocities at sections in the directions of the $x$ and the $y$ axis, again for scenario (b). With the section in the direction of the $y$ axis as a spatial reference, streamlines depict main flow paths at different time frames during simulation. A rather turbulent and temporarily significantly changing flow pattern characterises the situation inside the building. Initially, as long as the basement level is not entirely filled, the fluid enters the building mainly via light shaft $\mathrm{s} 3$ and the flow field in the building has a distinctive rotational character. As simulation time progresses, the flow pattern becomes more and more disordered and flow in both directions occurs at the openings of the building envelope as well as on the inside.

Initially, maximum depth averaged velocities up to $5 \mathrm{~ms}^{-1}$ occur inside the building. These maxima are spatially limited to the vertical drops at the light shafts. Subsequently and, if focusing on the conditions on the basement level, with increasing filling ratio of the building volume, flow velocities significantly decrease and approach almost zero values.

In the following, the simulation results for building scenario (b) are compared with those for scenario (a), the reference case with the blocked building. An analysis is firstly made for the wetting progress at the outside of the building envelope. Figure 8, top line, illustrates the chronological sequence of the wetted area / total area ratios for the wall elements e 1 and e 5 on the building side facing the channel, for wall element e6 on the short side and for wall element e7 on the building side opposite to the channel (Fig. 4 and Table 1). Accordingly, the block diagrams in the lower line in Fig. 8 point out the wetting durations. The time-dependent ratios wetted area / total area of the wall elements are thereby classified and the number of simulation output time steps à $10 \mathrm{~s}$ 


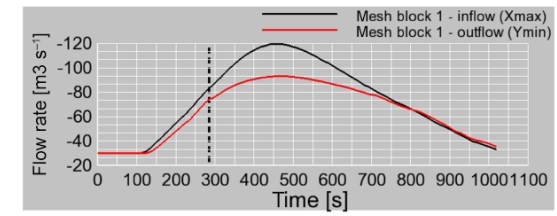

\section{Time $=285 \mathrm{~s}$}

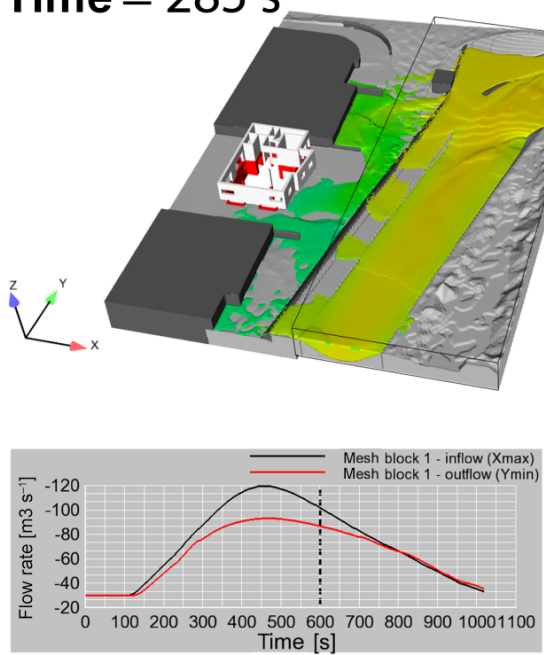

Time $=600 \mathrm{~s}$

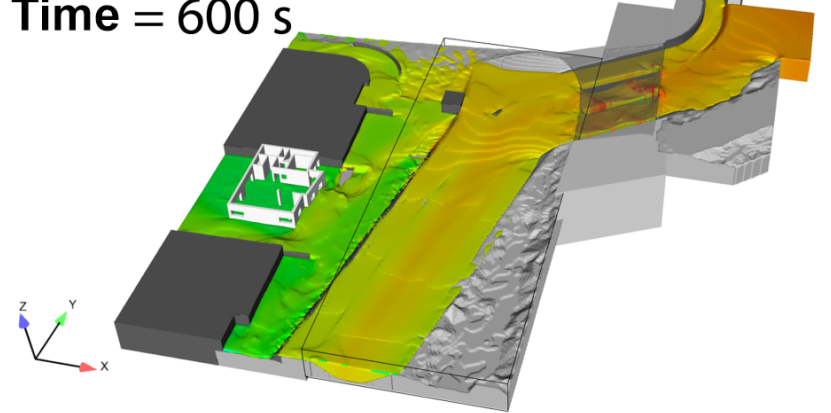

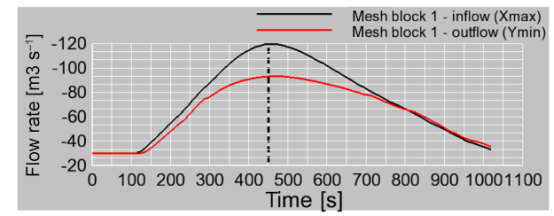
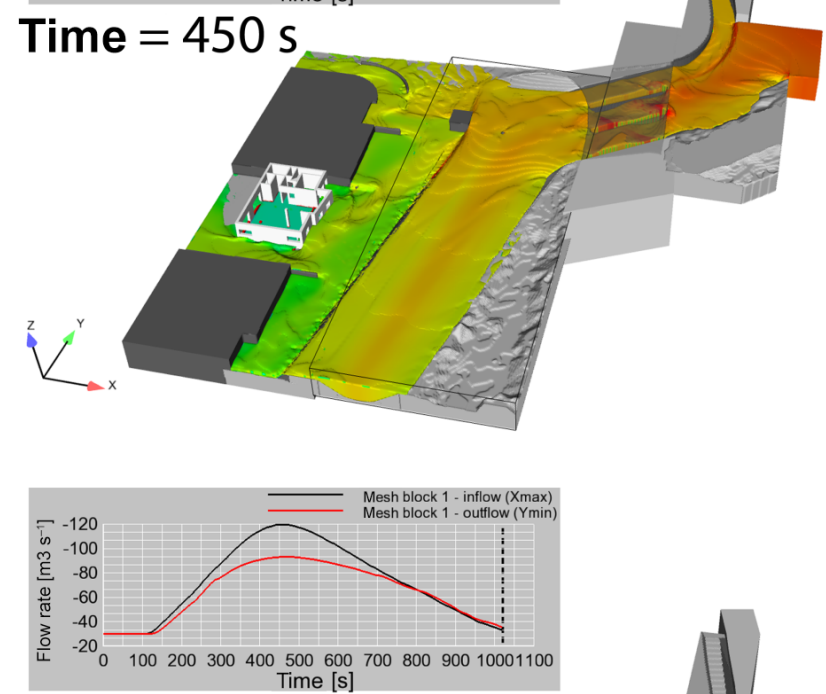

Time $=1020 \mathrm{~s}$

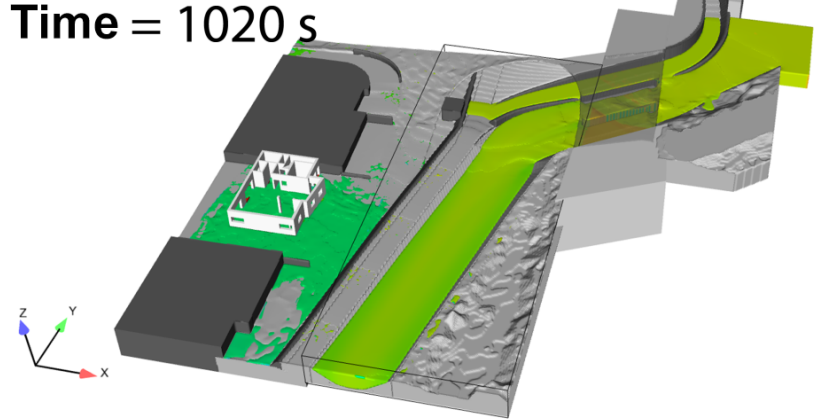

Figure 6. Modelling results for scenario (b) after 285, 450, 600 and $1020 \mathrm{~s}$ of simulation - perspective view of the stl-geometries and the fluid isosurface representing the total hydraulic head $(\mathrm{m})$, boundary flow rates (Xmax, Ymin) for mesh block mb1.

are analysed. Results for scenario (a) are coloured in black, the colour red is assigned to the results for scenario (b).

Concerning the peak ratios, there is only a marginal difference between the scenarios (a) and (b). A maximum wetting percentage of roughly $25 \%$ occurs at wall element e1 for both scenarios, the peaks at e5, e6 and e7 are 50\%, 50\% and $7.5 \%$ accordingly. The comparatively low wetted areas at the outside of wall element e7 are due to the fact that it is oriented to the south of the building and thus not directly exposed to the flow.

However, some significant differences between the two scenarios (a) and (b) can be observed in the temporal development of wetting. In the case of scenario (a), flow on the almost flat flood plain is prevented from entering the building at the light shafts ( 22 and $\mathrm{s} 3$ ). The wetting ratio at wall element e6 on the short side of the building features significantly higher values during the rising limb of the flood hydrograph. The plateau in the red line for wall element e6 until the time frame of $450 \mathrm{~s}$ marks the filling progress of the basement level. Once completely filled, water accumulates at the outside of wall element e6 and the wetting ratio increases rapidly. There is no significant difference at wall element e 6 between the scenarios during the falling limb of the hydrograph, except for a marginal lower water level for scenario (b) at the end of the simulation. The same holds for the characteristics of wetting at wall element e 5 on the building side facing the Rio Vallarsa channel. In accordance to the situation at wall element e6, e1 is also impacted more significantly during the rising limb of the hydrograph. Due to the blockage of the building, damming on the flood plain appears earlier, and the flow depths at wall element el increase accordingly.

As aforementioned wall element e7 on the building side opposite to the channel is not directly exposed to flooding. The fluid impact is higher for scenario (b) when the basement level is entirely filled and the fluid also exits throughout the 


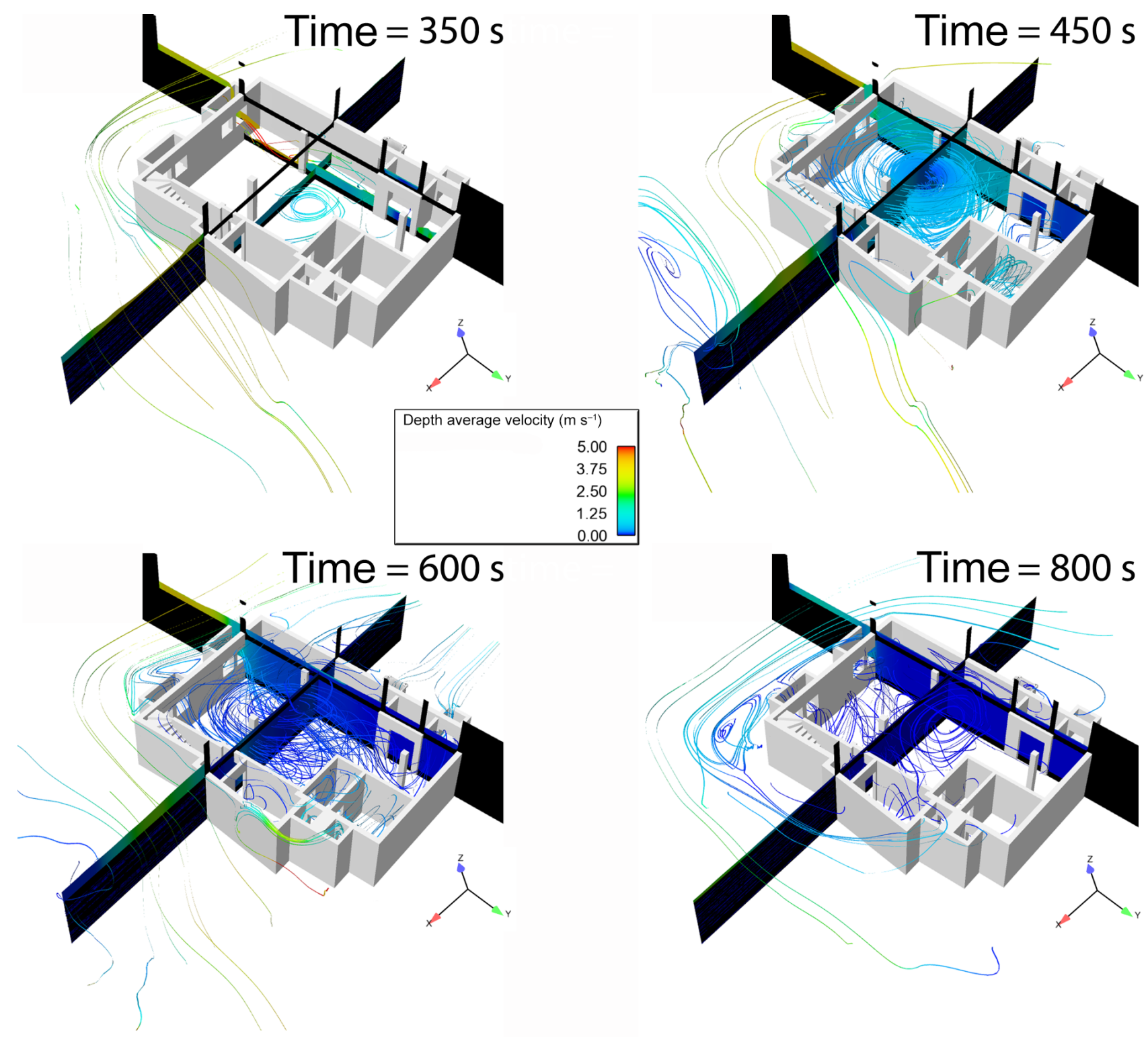

Figure 7. Scenario (b) after 350, 450, 600 and 1020 s of simulation - 2-D sections and streamlines with depth averaged velocity contours $\left(\mathrm{m} \mathrm{s}^{-1}\right)$, illustrating flow paths and characteristics of in- and outflow of the building (stl-geometry of the building).

openings of wall element e7. With it, the relative difference in wetting between both scenarios is highest at the building envelope not facing the Rio Vallarsa channel. With regard to the comparison in the block diagrams, durations with lower wetting ratios are on an average higher for scenario (b), whereas higher wetting ratios are lower. This holds for the wall elements e1, e5 and e6.

On the basis of the hydraulics at the building, the dynamically impacting fluid forces are analysed in Fig. 9, left. Force magnitudes at the first-floor-wall elements e1-e7 are compared for the scenarios (a) and (b). Concerning scenario (b), the impacts in- and outside the building are plotted individually (red dots in Fig. 9, left). Force magnitudes are calculated from the temporarily varying pressure and shear forces; they represent the maximum total force on the wall element within the entire simulation period.

Firstly focusing on the outside of the building, maximum impacts with values in the range $22-28 \mathrm{kN}$ occur at the wall elements e 3 and $\mathrm{e} 5$ on the building side facing the Rio Vallarsa channel. The force magnitudes at the remaining wall elements reach $10 \mathrm{kN}$ at maximum. At the wall elements e1, e4, e6 and e7, only a marginal difference between the two considered scenarios can be observed. Maximum impacting force at wall element e 2 is higher for scenario (a) and vice versa for the wall elements e 3 and e5. Impacting forces inside the building are in general lower than on the outside. 

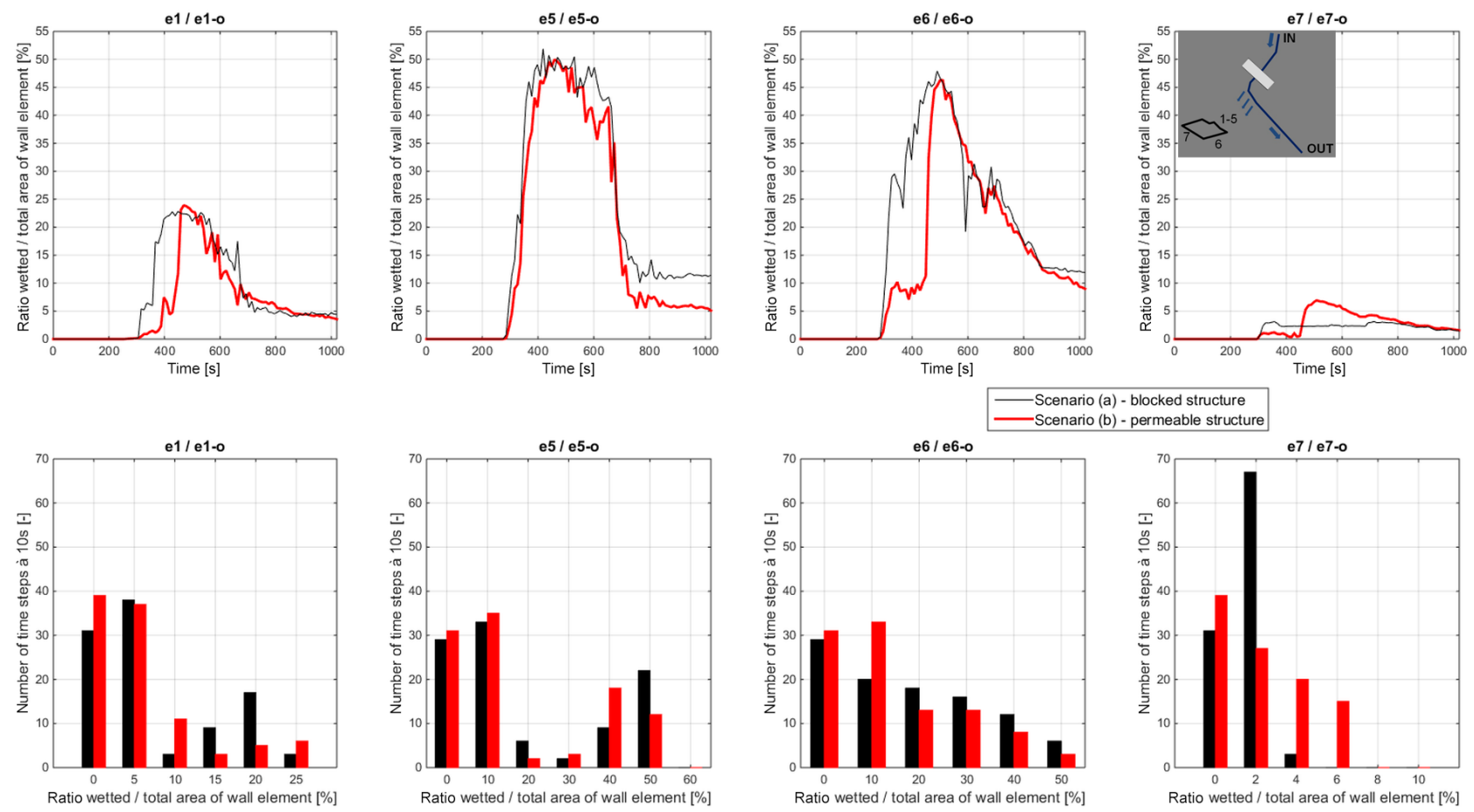

Figure 8. (Top line) ratio of wetted and total area of the wall elements e1, e5, e6 and e7 at the outside of the building for the scenarios (a) and (b); (lower line) comparison of wetting durations (number of time steps à $10 \mathrm{~s}$ ) for the considered wall elements.
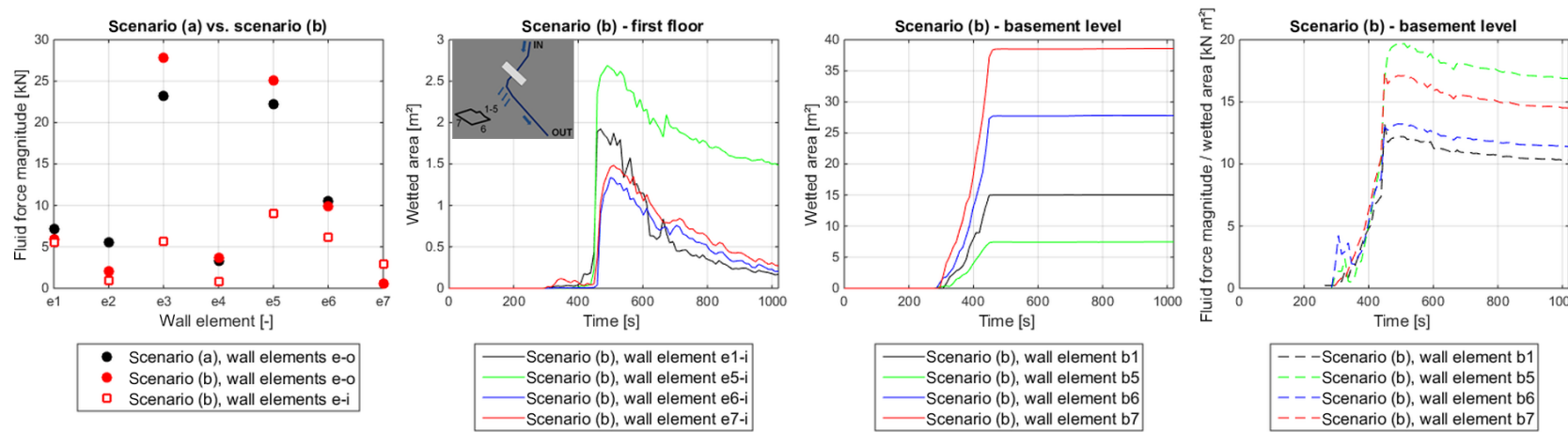

Figure 9. (Left) fluid force magnitudes $(\mathrm{kN})$ on the building envelope for the scenarios (a) and (b); (middle) wetted areas of wall elements $\left(\mathrm{m}^{2}\right)$ inside the building for scenario (b); (right) specific fluid force magnitudes $\left(\mathrm{kN} \mathrm{m}^{-2}\right)$ at wall elements on the basement level for scenario (b).

This is mainly due to the facts that (i) the fluid firstly fills the basement level and only insignificantly impacts the first floor at the inside at the beginning of the flooding and (ii) the force components due to the dynamics of the fluid (lower velocities) are comparatively lower.

With regard to scenario (b), Fig. 9 further shows the wetted area in function of the time each for the wall elements e1-i, e5-i, e6-i and e7-i on the first floor and the corresponding wall elements on the basement level. Concerning the latter, wetting ratios reach a value of 1.0 after $450 \mathrm{~s}$ of simulation and remain constant until the end of simulation. Due to the characteristics of the building structure, wetting on the first floor starts after $450 \mathrm{~s}$ of simulation, rapidly reaches its maximum after $470-530 \mathrm{~s}$ of simulation and certainly decreases until the end of simulation. The present interaction between the fluid bodies on the basement level and the first floor can be observed in Fig. 9, right: Maximum specific forces, meaning the ratio of fluid force magnitude and wetted area, appear at the time of the maximum flow depth on the first floor. The decrease in water level during the falling limb of the hydrograph leads to a decrease of hydrostratic pressure and, consequently, specific forces. However, compared to the water body on the basement level, the influence of the fluid in the first floor is relatively small. 


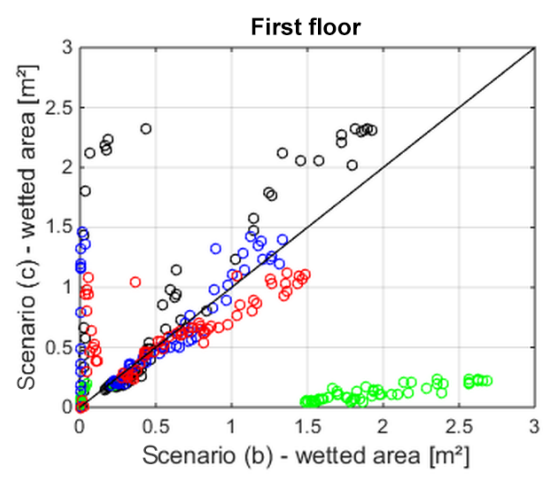

- Wall element e1-i

- Wall element e5-i

- Wall element e6-i

- Wall element e7-i

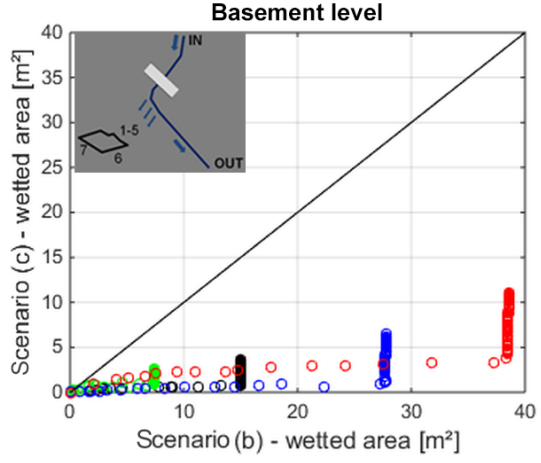

- Wall element b1

Wall element b5

- Wall element b6

Wall element b7

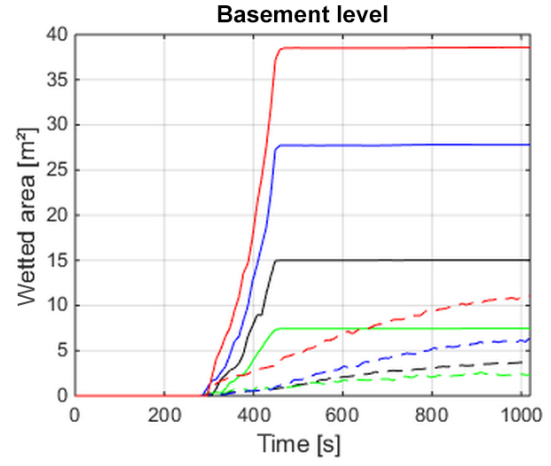

\begin{tabular}{|r|}
\hline- Scenario (b), wall element b1 \\
--- Scenario (c), wall element b1 \\
- Scenario (b), wall element b5 \\
--- Scenario (c), wall element b5 \\
- Scenario (b), wall element b6 \\
--- Scenario (c), wall element b6 \\
- Scenario (b), wall element b7 \\
--- Scenario (c), wall element b7
\end{tabular}

Figure 10. Comparison of wetted areas $\left(\mathrm{m}^{2}\right)$ during the simulations of the scenarios (b) and (c) - (left) wall elements e1, e5, e6, e7 on the first floor inside the building; (middle) wall elements b1, b5, b6 and b7 on the basement level (simulation results with output time steps à $10 \mathrm{~s}$ ); (right) temporal characteristics of wetting for the wall elements on the basement level for the scenarios (b) and (c).

If changing the opening characteristics of the building, the fluid impact inside the building is significantly different, not necessarily going along with an exclusive decrease of impacts if specific local structural protection measures are built. This aspect is shown in Fig. 10 by means of a comparison of the scenarios (b) and (c). Wetted areas of the wall elements e1-i, e5-i, e6-i and e7-i on the first floor are compared (left diagram). The situation on the basement level is shown in the middle and left diagram.

In the case of scenario (c), the process of flooding the building occurs in a way other than for scenario (b): The initial fluid influx via the light shafts is disabled due its covering and raise. The fluid enters the building through the doors and windows on the first floor, stays and spreads in the building and partially leaves again. The basement level is filled from the fluxes inside via the staircases; it does not get fully filled during the entire simulation period. Accordingly, wetted areas and impacting forces on the basement level are significantly lower for scenario (c) than for scenario (b). Higher impacts occur for scenario (c) on the first floor, except for wall element e5 on the building side facing the Rio Vallarsa channel. This wall element is affected only marginally due to the facts that the bordering staircase $\mathrm{sc} 2$ is placed directly in front and the fluid on the basement level does not reach the storey ceiling. Within this context it has to be noted that the scenarios (b) and (c) do not fully accurately represent the pure natural behaviour of the building in the case of flooding. Doors and windows are assumed to be fully open during the entire duration of the flood hydrograph. At real conditions, if not protected with specific sealing and reinforcement features, they are expected to have neither a full blocking nor an open but a partially permeable effect. However, simulation scenario (c) highlights the need of an excellent planning procedure for building hazard-proof buildings in order to achieve efficient and reliable flood protection.

Whereas from a building's durability point of view the impact of flooding is of basic relevance, the way of considering a certain element at risk within numerical modelling seems to insignificantly influence the flow field on the surrounding flood plain. To give an impression on this process of mutual influence, Fig. 11 illustrates time-dependent flow data at the boundaries of mesh block mb2. The differences of discharges between scenarios (b) and (a) (red lines in Fig. 11, left and middle) and as well between scenarios (c) and (a) (blue lines in Fig. 11, left and middle) are related to the maximum boundary outflow for scenario (a) and plotted as absolute values against time at the boundaries Xmin, Xmax and Ymin of mesh block mb2. Mesh block mb2 covers the flood plain orographically right to the channel (Fig. 6) where a certain influence of the building is expected.

The maximum average relative difference between the scenarios (b) and (a) is $2.7 \%$. Comparison of the scenarios (c) and (a) reveals a maximum difference of $1.9 \%$ on average. Xmin represents the inflow boundary for mesh block mb2. Fig. 11 points out that a minor influence of the building on the surrounding flow field not only appears in the downstream direction where the building acts as a small retentional element. The building means also an obstacle and influences the flow on the flood plain towards upstream. A comparison of the total discharge volumes at the outflow boundaries of mesh block $\mathrm{mb}$, again in relation to the simulation time, are highlighted in Fig. 11, right. Related to the total discharge volume 

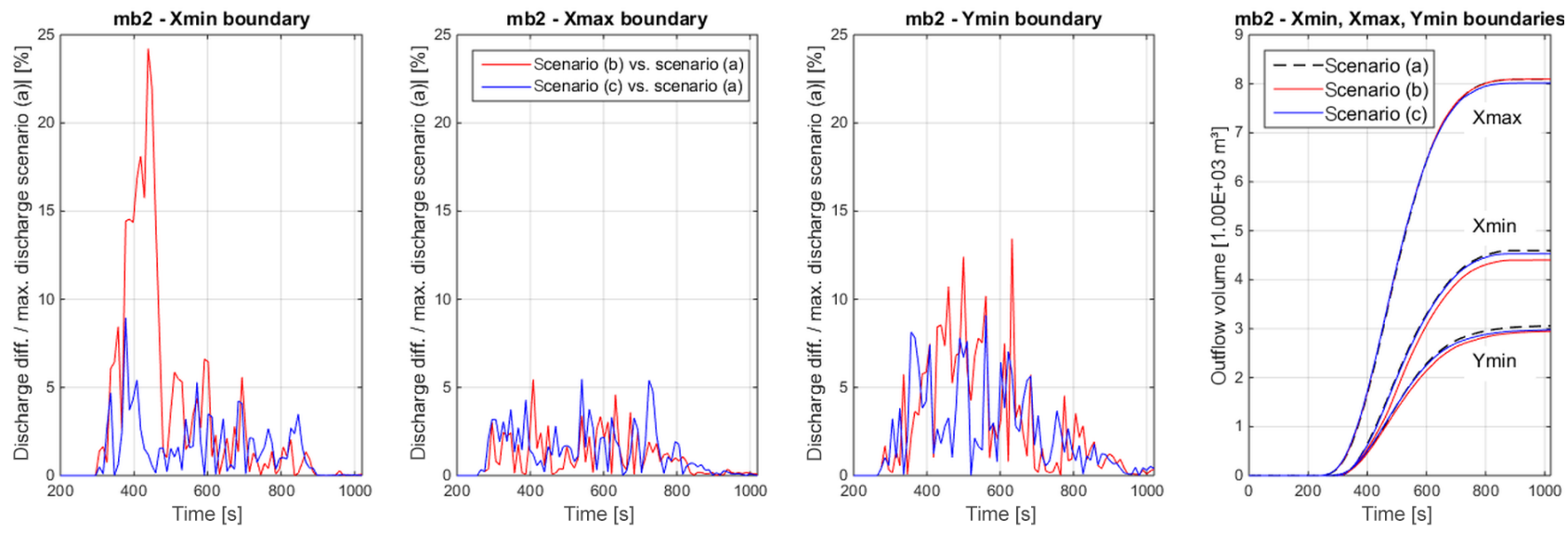

Figure 11. Discharges at the boundaries Xmin, Xmax and Ymin of mesh block mb2 (Fig. 5) - (left and middle) time-dependent discharge differences between scenario (b) and (a) in relation to the maximum discharge of scenario (a) at the considered boundaries; (right) scenariospecific outflow volumes at the boundaries.

of the flood hydrograph $\left(720270 \mathrm{~m}^{3}\right)$, a total of $2.1 \%$ passes the boundaries of mesh block mb2 for scenario (a). A comparison of the scenarios with each other reveals volume ratios within the range $0.9579-1.0002$.

Differences in flow parameters (water depths, velocities) between the considered building scenarios are as well small, except for the area inside the building and very close to the building envelope. They are considerably smaller within the computational domain than at the model boundaries.

\section{Discussion and conclusions}

\subsection{Fluid-building interaction - general relevance of indoor flooding processes under clear water conditions}

The results of hydrodynamic numerical modelling (Sect. 2.5) show a rather marginal influence of the building on the flow field on the flood plain and in the Rio Vallarsa channel. Due to the small interior volume of the building compared to the volume of the simulated flood hydrograph, this behaviour is more or less independent from the way of considering the element at risk within the simulation model (Fig. 11). If not for scaling the expected hydrograph (by a factor of 0.1 in order to cope with the computational effort) and perfectly simulating real conditions, this influence would be considerably smaller.

Otherwise, focusing on the impact of the fluid on the inside of the building, a certain impact can be observed. This impact on the inside is mainly characterised by relatively small flow velocities (Fig. 7) but long wetting durations that basically extend beyond the duration of the hazard event. The impact (Fig. 9) does not threaten the stability of the building (limit states ULS according EN 1990, Sect. 1) but affects the building physics and, with it, the usability (limit states
SLS according EN 1990, Sect. 1). The latter may cover also potential serious damage of electrical and in-house installations, furnishing and equipment. This kind of damage will be considerably higher under real conditions, when fine sediments (suspended load) that pass the debris retention dam, contribute also and get deposited inside the building. A significant impact on the stability of the building probably requires the contribution and consideration of conditions with intense sediment loads (WST and DBF according Heiser et al., 2015) or rather the modelling of geo-mechanical processes (Sect. 1).

However, with regard to the danger to life and limb inside buildings, numerical modelling under clear water conditions is highly valuable. The characteristics of flooding the building provide information for evacuation planning or rather non-affected areas during hazard events.

With regard to the transferability of the results of the present case study analysis to buildings in other regions, knowledge about the applicability and the limits of the chosen modelling approach are of use rather than the delivered impact values and wetting durations. As illustrated in Sect. 2.5, modelling results are significantly influenced by the characteristics of the design flood, most notably by the volume of the discharge hydrograph that exceeds the capacity of the brick work channel. Also topography, land use and the settlement structure of the surrounding floodplain are influencing parameters. The general knowledge of a reasonable application of three-dimensional models for simulation of indoor flooding processes and, further, its computational limits (Sect. 3.3) represent the basic added value for general issues and plans in flood risk management. 


\subsection{Fluid-building interaction with different hydrological modelling scenarios - comparison of an unsteady and a steady-state modelling approach}

The simulation results presented in Sect. 2.5 exclusively focus on the unsteady hydrological scenario, specified as 300 -year torrential hazard and design event for flood risk management (Sect. 2.4). The present computational domain and element at risk was already studied by Hofer (2014) in terms of a steady-state analysis of specific hazard scenarios. Hofer (2014) simulated specific discharges up to $120 \mathrm{~m}^{3} \mathrm{~s}^{-1}$ and analysed wetted areas and impacts on the considered building at the end of each simulation when steady-state conditions were achieved within the computational domain. Criteria for the steady-state condition were thereby mainly focused on the fluxes at the mesh block boundaries. In analogy with the unsteady modelling approach, the three building scenarios (a), (b) and (c) were analysed (Sect. 2.3).

When qualitatively comparing the results of the two different modelling approaches and reflecting the propagation of flooding in the unsteady scenario simulation, the process of filling the interior volume of the building can obviously not be adequately modelled with a steady-state simulation. The basement level of the building is getting fully filled up until the end of steady-state simulation independently from flood discharge, only the required simulation time changes accordingly. As the evaluation of results is carried out solely at the end of the steady-state simulations when the maximum fluid impacts are supposed to appear, this presumed "unnatural" process of filling the building certainly distorts the modelling results. Depending on the characteristics of the design flood (discharge volume), the retention effect of the considered building is thereby either under- or overestimated: An underestimation is observed at conditions in which the considered building is in fact flooded, but the duration of overbank flooding within unsteady modelling is less than the steady state modelling duration. An overestimation possibly appears at conditions with very short durations of overbank flooding and impacting, as a steady state model, assuming a constant peak discharge, unnaturally extends these durations. This statement is further underpinned by the fact that, with the unsteady simulations, maximum potential impacts may appear also at conditions, when both the basement level and the first floor of the building are filled but the water level on the basement level does not necessarily reach the storey ceiling (Figs. 6 and 8). The time of maximum impacts is thus mainly dependant on the characteristics of the flood hydrograph. Further, with regard to an analysis of expected wetting durations (Fig. 8), a steady-state modelling approach does not allow any conclusions. Against this background, differences in fluid impacts resulting from unsteady and steadystate modelling are observed mainly for scenarios, where indoor flooding actually appears to a rather less extent. This is the case for scenario (c) for example. Consideration of volume of the flood hydrograph seems at least equally important as the flood peak. Further, the differences of the results for the three considered building scenarios are less pronounced with the steady-state simulations.

A qualitative comparison of the steady-state and the unsteady modelling results reveal an underestimation of the impacts on the building for the steady-state simulations with the $120 \mathrm{~m}^{3} \mathrm{~s}^{-1}$ discharge. Further details and results of the steady-state simulations can be found in Hofer (2014).

Irrespective of the capabilities and constraints of both modelling approaches, it has to be noted that the steady-state simulations require a substantially lower computational effort. This is due to shorter simulation times leading up until the simulations reach steady-state conditions compared to the duration of the discharge hydrographs.

Summarising, the applicability of the steady-state modelling approach is reasonable in the context of preliminary studies with the objective of verifying the general appearance of indoor flooding processes for specific hydrological conditions or analysing the effects of local structural protection measures in terms of entirely preventing indoor flooding.

\subsection{Computational modelling effort - capabilities and limits for practical application in flood risk management}

Under given effort of hydrodynamic numerical modelling and with consideration of the illustrated intensity of the fluid-building interaction (Sects. 2.5, 3.1 and 3.2), the basic question, whether there is any sense in considering indoor flooding processes in practical application, arises. Figure 12 provides performance details from the unsteady numerical calculations. The left diagram shows the computation times for the scenarios (a), (b) and (c), each in relation to the simulation time. Accordingly, the middle diagram presents the applied time step sizes and the diagram on the right points out the computation times per time step in relation to the simulation time.

Basically, all accomplished computations require long computing times compared to the simulation time or rather real time conditions. With the use of an Intel core i7-3820 quad-core processor (@3.60 GHz), 32 GB main memory and a parallel software license code, computation times of about $200 \mathrm{~h}$ are achieved for the scenarios (a) and (b), without any substantial differences between these scenarios. The time step sizes generally decrease with the occurrence of flooding and spreading on the flood plain. The computation time per time step features an almost linear relation to the fluid surface area within the computational domain, again with an insignificant influence of the building flooding process.

With $425 \mathrm{~h}$ computation time, simulation of scenario (c) is much more costly. This is due to the flow characteristics inside the building: The time step size significantly decreases when the fluid enters the building after about 320 s of simulation time. In contrast to scenario (b), the filling of the basement level occurs via the staircases from this point in time. 

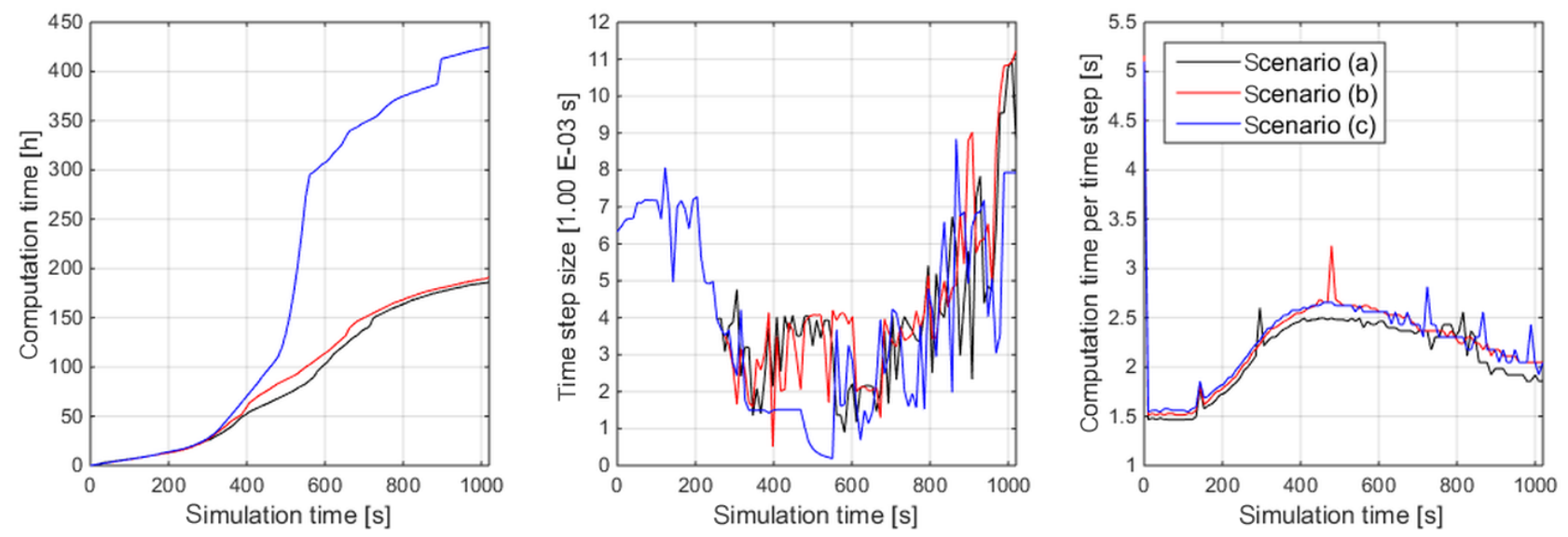

Figure 12. Computational effort - comparison of computation time (h) (left), time step size (1.0 E-3 s) (middle) and computation time per time step (s) (right) for the scenarios (a), (b) and (c).

The flow on these fine-structured, stepped obstacles leads to an adjustment of the time step size.

In a more general sense, 3-D hydrodynamic modelling of flood hydrographs and the spreading on a flood plain is a very time-consuming task, even though rather small computational domains ( 0.564 ha in this study) are analysed. The computational effort can but does not necessarily have to further increase if building flooding processes are considered. This statement is underpinned by the fact that for the unsteady scenario simulation the expected design flood was adapted by a scale factor of 0.1 (Sect. 2.3) in order to achieve manageable computation times. Practical application in flood risk mapping, typically covering a larger extent of the flood plain and at least a couple of elements at risk, seems to not be practicable (or mandatory) in this context. Compared to the rather small influence of a permeable building structure on the flow field on the surrounding flood plain, a potential significant increase of computation time is furthermore not reasonable.

However, for vulnerability analysis and the planning of local structural protection measures for specific elements at risk, the modelling of building flooding processes means a valuable tool. Specific planning options can be tested and verified on their efficiency. They can be further compared with each other within a cost-benefit analysis where potential hazard impacts or rather avoided impacts and damages are considered. Compared to the general expense of the planning process and, for the case of an insufficient efficiency of the measures due to a poor planning, to the extent damages, the costs for numerical modelling and scenario simulation is perfectly acceptable.

\section{Aspects of further research}

The assessment of the specific vulnerabilities of the built environment is the pillar for any planning process that is tar- geted at a reduction of the expected adverse consequences. These adverse consequences result from the interactions between the hazard processes and the exposed elements, both in time and space. From a physical perspective, these interactions firstly take the form of damage-generating mechanisms, which are quantifiable knowing the hazard intensities and the physical response of the structures in terms of (i) deformations with respect to the admissible states, (ii) the wetting process of the buildings envelope and its alterations. Given specified loading conditions and determined geometrical and material properties of the building envelope, the subsequent mass transport processes through it may result in secondary damage-generating mechanisms.

This work represents a step towards the development of a comprehensive physical vulnerability assessment framework and shows how advanced modelling techniques may be usefully employed for pure water floods. However, further research efforts are needed (i) to develop reliable and practicable 3-D codes for the whole spectrum of flow processes involving sediment transport at various rates and featuring different non-Newtonian flow behaviours, (ii) to couple the simulation of flow dynamics with structural mechanics. In parallel, if the aforementioned advances are feasible, it is fundamental to provide for effective, easy handling and cheap methods as terrestrial photogrammetry to create highresolution building models. Additionally, it is essential to optimize the physical parameterization (i.e. material properties) of such models. In this context, physical scale model experiments could provide novel and valuable insights.

Self-evidently, only a limited number of key elements of the built environment should be analysed to such a level of detail; therefore a harmonisation with the available vulnerability information for the remaining exposed elements is necessary.

To conclude, it has to be remarked that reducing physical vulnerability is a necessary but not sufficient flood risk 
mitigation strategy. Conceiving vulnerability as a continuum along the risk cycle with respect to both, space and time, considerable efforts should be devoted to significantly enhance the societal capacities to cope with and recover from the remaining adverse effects of occurring flood events. Last but not least it is essential that post-event design processes aim at reconfiguring the flood prone system by avoiding serious damage-generating mechanisms and not at reconstructing the elements of the built environment featuring the same old set of vulnerabilities.

Acknowledgements. The presented study was completed at the University of Innsbruck and in close collaboration with the Department of Hydraulic Engineering of the Autonomous Province of Bolzano. The Unit of Hydraulic Engineering thanks the Department of Hydraulic Engineering for this precious cooperation. Further thanks are due to the owner of the modelled element at risk for providing highly valuable plan documents of the building structure and experience of flood event characteristics, and, most notably, for keeping an open mind for scientific research.

The presented study was conducted during the review stage of a 3-year research project, funded by the Austrian Science Fund (FWF): P 27400-NBL. It provides valuable information on capabilities and limitations of numerically modelling the process-building interaction.

Edited by: K. Schröter

Reviewed by: two anonymous referees

\section{References}

Alexander, D. E.: Confronting Catastrophe: New Perspectives on Natural Disasters, Harpenden, UK and New York, Terra and Oxford University Press, p. 5, 2000.

Armanini, A. and Scotton, P.: Experimental analysis on the dynamic impact of a debris flow on structures, Proceedings of the Interpraevent 1992, Bern, Vol. 6, 107-116, 1992.

Carter, W. (Ed.): The disaster management cycle, Disaster management: a disaster manager's handbook, Manila, Philippines: Asian Development Bank, 51-59, 1991.

Chiari, M.: Numerical Modelling of Bedload Transport in Torrents and Mountain Streams, doctoral thesis, Institute of Mountain Risk Engineering, University of Natural Resources and Life Sciences Vienna (BOKU), 2008.

Department of Hydraulic Engineering, Autonomous Province of Bolzano - South Tyrol: Ricostruzione dell'evento del 11.11.2012, unpublished.

Fell, R., Corominas, J., Bonnard, C., Cascini, L., Leroi, E., and Savage, W.: Guidelines for landslide susceptibility, hazard and risk zoning for land-use planning, Eng. Geol., 102, 85-98, 2008.

Flow Science Inc.: FLOW-3D, v10.0, user manual, 2012.

Fuchs, S.: Susceptibility versus resilience to mountain hazards in Austria - paradigms of vulnerability revisited, Nat. Hazards Earth Syst. Sci., 9, 337-352, doi:10.5194/nhess-9-337-2009, 2009.

Fuchs, S.: Mountain hazards, vulnerability, and risk - a contribution to applied research on human-environment interaction. Habilita- tion thesis at the University of Innsbruck, Austria, 2009, unpublished.

Fuchs, S., Heiss, K., and Hübl, J.: Towards an empirical vulnerability function for use in debris flow risk assessment, Nat. Hazards Earth Syst. Sci., 7, 495-506, doi:10.5194/nhess-7-4952007, 2007.

Gabl, R., Gems, B., De Cesare, G., and Aufleger, M.: Anregungen zur Qualitätssicherung in der 3-D-numerischen Modellierung mit FLOW-3D, WasserWirtschaft - Fachzeitschrift für Wasser und Umwelttechnik 03/2014, 15-20, doi:10.1365/s35147-014-0938$0,2014$.

Gems, B.: Entwicklung eines integrativen Konzeptes zur Modellierung hochwasserrelevanter Prozesse und Bewertung der Wirkung von Hochwasserschutzmaßnahmen in alpinen Talschaften - Modellanwendung auf Basis einer regionalen Betrachtungsebene am Beispiel des Ötztales in den Tiroler Alpen Forum, doctoral thesis, Unit of Hydraulic Engineering, University of Innsbruck, Innsbruck University Press (IUP) (=Forum Umwelttechnik und Wasserbau, 13), 2012.

Gems, B., Wörndl, M., Gabl, R., Weber, C., and Aufleger, M.: Experimental and numerical study on the design of a deposition basin outlet structure at a mountain debris cone, Nat. Hazards Earth Syst. Sci., 14, 175-187, doi:10.5194/nhess-14-175-2014, 2014a.

Gems, B., Sturm, M., Vogl, A., Weber, C., and Aufleger, M.: Analysis of damage causing hazard processes on a torrent fan - scale model tests of the Schnannerbach Torrent channel and its entry to the receiving water, Digital Proceedings of the Interpraevent 2014 in the Pacific Rim, Nara, 2014b.

Gems, B., Sturm, M., Aufleger, M., and Neuner, J.: Reconstruction of event-related bed-load transport processes in alpine catchments - application of TomSed on a large spatial scale, in: River Flow 2014, edited by: Schleiss, A. J., de Cesare, G., Franca, M. J., and Pfister, M.: Proceedings of the 7th International Conference on Fluvial Hydraulics, London, Taylor \& Francis, ISBN 978-1-138-02674-2, 941-949, 2014c.

Giesecke, J., Heimerl, S., and Mosonyi, E.: Wasserkraftanlagen - Planung, Bau und Betrieb, 6. aktualisierte und erweiterte Auflage, Springer-Verlag Berlin Heidelberg, p. 204, doi:10.1007/978-3-642-53871-1, 2014.

Habersack, H., Hengl, M., Knoblauch, H., Reichel, G., Rutschmann, P., Sackl, B., and Tritthart, M.: Fließgewässermodellierung - Arbeitsbehelf Hydrodynamik; Grundlagen, Anwendungen und Modelle für die Praxis, ÖWAV-Arbeitsbehelf, 37, 2007.

Heiser, M., Scheidl, C., Eisl, J., Spangl, B., and Hübl, J.: Process type identification in torrential catchments in the eastern Alps, Geomorphology, 232, 239-247, 2015.

Hofer, T.: 3D-numerische Modellierung der Durch- und Umströmung von Infrastrukturobjekten (Gebäuden), master thesis, Unit of Hydraulic Engineering, University of Innsbruck, 2014.

Holub, M., Suda, J., and Fuchs, S.: Mountain hazards: reducing vulnerability by adapted building design, Environ. Earth Sci., 66, 1853-1870, doi:10.1007/s12665-011-1410-4, 2012.

Hübl, J., Jugovic, J., Erlmoser, M., Steinwendter, H., Holzinger, G., and Gruber, H.: Hydraulische Modellversuche zur Optimierung des Mündungsbereiches des Schwarzbaches in die Leoganger Ache, IAN Report 43-2, Institute of Mountain Risk Engineer- 
ing, University of Natural Resources and Applied Life Sciences, Vienna, 2002.

Hufschmidt, G.: A comparative analysis of several vulnerability concepts, Nat. Hazards, 58, 621-643, 2011.

Hunzinger, L. and Zarn, B.: Sediment Transport and Aggradation Processes in Rigid Torrent Channels. Proceedings of the Interpraevent 1996, Garmisch-Partenkirchen, Vol. 4, 221-230, 1996.

in.ge.na engineering office: Hydrogeologischer Gefahrenzonenplan, Gemeinde Leifers - Ausführlicher Bericht Wassergefahren/Piano delle zone di pericolo idrogeologico, commune di Laives - Relazione dettagliata pericoli idraulici, unpublished.

Kappes, M., Keiler, M., von Elverfeldt, K., and Glade, T.: Challenges of analyzing multi-hazard risk: a review, Nat. Hazards, 64, 1925-1958, 2012a.

Kappes, M., Papathoma-Köhle, M., and Keiler, M.: Assessing physical vulnerability for multihazards using an indicator-based methodology, Appl. Geogr., 32, 577-590, 2012b.

Kienholz, H., Krummenacher, B., Kipfer, A., and Perret, S.: Aspects of integral risk management in practice - considerations with respect to mountain hazards in Switzerland, Österreichische Wasser und Abfallwirtschaft, 56, 43-50, 2004.

Landesanstalt für Umweltschutz Baden-Württemberg: Hydraulik naturnaher Fließgewässer, Teil 2 - Neue Berechnungsverfahren für naturnahe Gewässerstrukturen, 1. Auflage, Karlsruhe, 47-49, 2002.

Mazzorana, B., Levaggi, L., Formaggioni, O., and Volcan, C.: Physical vulnerability assessment based on fluid and classical mechanics to support cost-benefit analysis of flood risk mitigation strategies, Water, 4, 196-218, doi:10.3390/w4010196, 2012a.

Mazzorana, B., Levaggi, L., Keiler, M., and Fuchs, S.: Towards dynamics in flood risk assessment, Nat. Hazards Earth Syst. Sci., 12, 3571-3587, doi:10.5194/nhess-12-3571-2012, 2012 b.

Mazzorana, B., Comiti, F., and Fuchs, S.: A structured approach to enhance flood hazard assessment in mountain streams, Nat. Hazards, 67, 991-1009, 2013.
Mazzorana, B., Simoni, S., Scherer, C., Gems, B., Fuchs, S., and Keiler, M.: A physical approach on flood risk vulnerability of buildings, Hydrol. Earth Syst. Sci., 18, 3817-3836, doi:10.5194/hess-18-3817-2014, 2014.

Papathoma-Köhle, M., Kappes, M., Keiler, M., and Glade, T.: Physical vulnerability assessment for alpine hazards: state of the art and future needs, Nat. Hazards, 58, 645-680, 2011.

Papathoma-Köhle, M., Keiler, M., Totschnig, R., and Glade, T.: Improvement of vulnerability curves using data from extreme events: debris flow event in South Tyrol, Nat. Hazards, 64, 20832105, 2012.

Rosatti, G. and Begnudelli, L.: Two-dimensional simulation of debris flows over mobile bed: enhancing the TRENT2D model by using a well-balanced generalized roe-type solver, Comput. Fluids, 71, 171-195, 2013.

Scheidl, C., Chiari, M., Kaitna, R., Müllegger, M., Krawtschuk, A., Zimmermann, T., and Proske, D.: Analysing Debris-Flow Impact Models, Based on a Small Scale Modelling Approach, Surv. Geophys., 34, 121-140, 2013.

Totschnig, R. and Fuchs, S.: Mountain torrents: quantifying vulnerability and assessing uncertainties, Eng. Geol., 155, 31-44, 2013.

Tsakiris, G.: Flood risk assessment: concepts, modelling, applications, Nat. Hazards Earth Syst. Sci., 14, 1361-1369, doi:10.5194/nhess-14-1361-2014, 2014.

Vetsch, D., Rousselot, P., Volz, C., Vonwiller, L., Peter, S., Ehrbar, D., Gerber, M., Faeh, R., Farshi, D., Mueller, R., and Veprek, R.: System Manuals of BASEMENT, Version 2.4. Laboratory of Hydraulics, Glaciology and Hydrology, ETH Zurich, available at: http://www.basement.ethz.ch (last access: April 2015), 2014.

Wisner, B.: Assessment of capability and vulnerability, in: Mapping vulnerability, Disasters, development and people, edited by: Bankoff, G., Frerks, G., and Hilhorst, D., Earthscan, London, 183-193, 2004. 